\title{
EFFECT OF AMYGDALUS EBURNEA ON THIRD-DEGREE BURNS IN RATS AND COMPARISON WITH SILVER SULFADIAZINE OINTMENT
}

\author{
MEHDI REZAEIFAR ${ }^{1}$, MARYAM REZAEIFAR ${ }^{2 *}$ \\ ${ }^{1}$ Department of Pharmaceutics, Faculty of Pharmacy, Kerman University of Medical Sciences, Kerman, Iran. ${ }^{2}$ Student Research Committee, \\ Tehran University of Medical Sciences, Tehran, Iran. Email: mrezaeifar@gmail.com
}

Received: 31 December 2016, Revised and Accepted: 02 March 2017

\section{ABSTRACT}

Objective: Amygdalus eburnea is a perennial herb that has been valued for its important biological perspectives and it has been used to treat the burn. This study aims to evaluate wound healing activity of $A$. eburnea extract compared with silver sulfadiazine (a synthetic burn ointment) for treating the induced third-degree burn in rat.

Methods: In this study, a deep, third-degree burn wound was induced by a hot plate warmed 5 minutes within boiling water and placed for 3 seconds on the skin. The shell root of A. eburnea an Iranian medicinal herb is investigated on its wound healing activity in comparison with silver sulfadiazine ointment as the standard treatment for burn wound in rats.

Results: Our results demonstrated that $A$. eburnea can be an effective treatment for third-degree burns. Advanced clinical and pharmaceutical studies are recommended to the production of novel natural drugs for burn wound treatment.

Conclusion: A. eburnea can be an effective treatment for third-degree burns. Advanced clinical and pharmaceutical studies are recommended to the production of novel natural drugs for burn wound treatment.

Keywords: Amygdalus eburnea, Rat, Wound healing, Silver sulfadiazine, Burns.

(C) 2017 The Authors. Published by Innovare Academic Sciences Pvt Ltd. This is an open access article under the CC BY license (http://creativecommons. org/licenses/by/4. 0/) DOI: http://dx.doi.org/10.22159/ajpcr.2017.v10i5.16877

\section{INTRODUCTION}

Burn injury is a global public health issue especially for the developing [1] and undeveloped countries, which suffer from lack of adequate medical facilities. Burns are one of the most common forms of injury with devastating concerns [2]. Burn is tissue injury caused by heat, electricity, chemicals, radiation, etc. According to the depth, burn wounds are categorized as first degree (superficial), second degree (partial thickness), and third degree (full thickness) [3]. Dressing is required to protect against the environmental flora and evaporative heat loss and accentuate the healing period because thermal injury disrupts the protective barrier function of skin. The ultimate burn dressing wound is cheap and comfortable; it cause the burn to heal rapidly and it cleans the wound and devitalized tissue and debride fragments of separated eschar and have an antibacterial activity $[4,5]$. Wound healing is a complex process including many physiological actions and responses, requiring the collaborative effects of different cells and tissues [6]. Severe burn wounds must be treated rapidly since any delay may cause infection or postpone the healing process [3]. Most of the early treatments include topical application of medicaments are necessary to prevent infections [7]. In severe burns, septicemia and infection are the main factors of mortality among these patients [8]. Burn wound healing is still a challenge to modern medicine despite the discovery of several antiseptics [2]. Although many improvements have been made to treat burn injuries, the best treatment to hasten healing has not been reached yet [9].

Many of the synthetic drugs cause problems such as drug resistance and allergy. Hence, many scientists are trying to seek alternative drugs [10]. More than $80 \%$ of the world's population utilizes traditional medicines for various skin diseases [11]. Recently, the traditional usage of plants has received considerable attention for wound healing by the scientific community $[11,12]$. Approximately, one-third of all using traditional medicines are for the treatment of wounds and skin disorders, compared to only $1-3 \%$ of modern drugs $[13,14]$. Herbal products have moderate efficacy with no or less toxicity and are cheaper than synthetic drugs [15]. Medicinal plants can act as wound healing agents because of their vast variety of different constituents such as alkaloids, tannins, terpenoids, essential oils, saponins, flavonoids, fatty acids, and phenolic compounds [16], which have the capability to improve healing process of burn wound. Low cost, availability and fewer side effects such as allergy and drug resistance are other advantages of herbal remedies $[3,17,18]$.

Amygdalus eburnea Spach. is a plant from Rosaceae family and it is a type of almond which is naturally grown and distributed in Iran. This plant is called "Ghosk" in Persian, which has been used in semi-desert areas to control soil erosion and stabilized watersheds [19]. Moreover, it has been used as wound healing of burn since ancient time by people of southeast of Iran. In traditional Iranian medicine, A. eburnea has also been utilized successfully as laxative and anti-worm. Furthermore, brew of dermal tissue is used for cough, respiratory distress, and paregoric. Moreover, in modern medicine, various pharmacological properties such as antioxidant, antifungal, antibacterial, and antidermatophyte have been related to this plant [20-24]. This study aims to evaluate wound healing activity of $A$. eburnea extract compared with silver sulfadiazine (a synthetic burn ointment) for treating the induced thirddegree burn in rat.

\section{METHODS}

\section{Collection of plant materials}

The shell root of $A$. eburnea was collected from rural regions of from Baft district, the Southeast of Iran, in April 2013. They were identified by a botanist of the Botany Department of Shahid Bahonar University, Kerman, Iran. A voucher specimen of the plant materials was deposited at the Herbarium of Department of Pharmacognosy, School of Pharmacy, Kerman University of Medical Science, Iran (KF 1136). 
Preparing of extracts

About $100 \mathrm{~g}$ of powdered plant material was separately extracted by percolation method with methanol (80\%) and water successively for $72 \mathrm{hrs}$ in room temperature. The extracts were passed through filter paper (Whatman No. 3, Sigma, Germany) to remove plant debris. The extracts were finally concentrated in vacuum at $50^{\circ} \mathrm{C}$ using a rotary evaporator (Heidolph, Germany) and stored at $-20^{\circ} \mathrm{C}$, until testing [25-27].

\section{Thermal injury model \\ Ethical statement}

This study was conducted in strictaccordance with the recommendations in the guide for the Care and Use of Laboratory Animals of the National Institutes of Health. The protocol was approved by the Committee on the Ethics of Animal Experiments of the Kerman University of Medical Science (Permit Number: 1508). Moreover, all efforts were made to minimize suffering.

\section{Animals}

Mal Wistar rats weighing from 200 to $250 \mathrm{~g}$ were obtained from the Animal Breeding Stock Facility of Razi Institute of Iran (Karaj, Iran). Animals were housed in a colony room with a $12: 12 \mathrm{hrs} \mathrm{light/dark} \mathrm{cycle}$ at $21 \pm 2{ }^{\circ} \mathrm{C}$ and were handled according to standard protocols for the use of laboratory animals. During the tests, the temperature of the room and humidity were controlled. For the experiments, the animals were selected randomly into three groups: Topical A. eburnea treated group, topical silver sulfadiazine treated group, and untreated or control group.

\section{Establishment of third-degree burn wound}

A deep, third-degree burn wound was induced by a hot plate warmed 5 minutes within boiling water and placed for 3 seconds on the skin. Immediately after burn, animals received an intraperitoneal injection of $1 \mathrm{ml}$ normal saline to prevent shock caused by burns. Burns were dressed daily with A. eburnea extract in Group 1 and silver sulfadiazine in Group 2. Responses to the treatment were assessed by digital photography during the treatment until day 15.

\section{Wound analysis}

The wound closure rate was assessed by tracing the wound on day 3,6 , 12 and 15 then percentage of recovery of all groups was compared. Time to wound closure was defined when the wound bed was completely re-epithelialized and filled with new tissue. The wound healing rate was calculated with a formula as following:

Percent of wound=Area of remaining wound/Area of original wound $\times 100$

Percent of recovery=100-Percent of wound.

\section{Pathological study}

Pathology examination was carried out on the skin biopsies on the 6 and 12 days after injury. Skin biopsies were examined after blocking and preparing cuts of $3 \mu \mathrm{m}$ by microtome (Leitz 1512) and stained with hematoxylin-eosin.

\section{RESULTS AND DISCUSSION}

Wound healing rates were measured at day $3,6,12$, and 15 after the wounding. The effect of the extract on wound healing activity in rats compared with the control rats and silver sulfadiazine treated group values of $\mathrm{p}<0.05$ were considered as statistically significant. The average percent of wound healing rates on the $3^{\text {rd }}$ day for extract, silver and control group was $9.51 \%, 7.17 \%$ and $7.88 \%$, respectively. The overall average wound healing rates on the $3^{\text {rd }}$ day were $8.19 \%$ that the highest $(25.66 \%)$ and lowest $(-1.48 \%)$ wound healing rates on the $3^{\text {rd }}$ day were belonging to extract and silver group, respectively. However, the silver group shows highest and lowest $47.54 \%$ and $4.07 \%$ wound healing rates on the $6^{\text {th }}$ day. Nevertheless, in the $12^{\text {th }}$ and $15^{\text {th }}$ day, the procedure was same that the maximum wound healing rates that are belong to extract group were $79.74 \%$ and $90.32 \%$, respectively. In all groups, wound healing rates increased with time. A significant increase in the wound-healing activity was observed in the animals treated with the extract, compared with those received the control treatments. This investigate showed that healing percentage in A. eburnea extract was $85.91 \%$, while in silver groups was $81.50 \%$ and in control groups was $68.78 \%(\mathrm{p}<0.05)$. Therefore, healing percent progress on $A$. eburnean extract was more than silver sulfadiazine and control groups in all days, and healing percent progress on control group was loss than another group. Healing time in treatment with A. eburnean was significantly shorter than silver sulfadiazine.

According to the homogeneity of variances tests at day 3, 6, 12, and 15 confidence level are $0.338,0.502,0.115$, and $0.074(>0.05)$, respectively, and conclude that the variance is constant.

The one-way ANOVA is used to test for differences among control, extract and silver groups at day $3,6,12$, and 15 . Since the confidence interval on the $3^{\text {rd }}$ day and $6^{\text {th }}$ is 0.89 and 0.849 respectively $(p>0.05)$ can be said healing rate percentage are same for all three groups in these 2 days. Differences of wound healing rate percentage in extract and silver groups are not significant at $12^{\text {th }}$ day, but according to descriptive statistics, it can be concluded wound healing rate in control group is less than them. As a result, statistically, the percentage of wound contraction showed that there is high significant difference between the different groups in the $15^{\text {th }}$ day. Moreover, Tukey test demonstrates the difference of wound healing between silver and extract groups was not significant, but their percentage of healing rate was better than the control group. Investigate of wound healing rate in all days for three groups indicate that differences of wound healing surface area for all three groups were not significant, although the best results of wound healing in all days were obtained in extract group. The difference between silver and extract group was not significant, but in extract group, healing rate was better $7^{\text {th }}, 8^{\text {th }}$ and near the end of the study. However, healing rate in control group was similar to that of extract and silver group in $1^{\text {st }}, 2^{\text {nd }}, 6^{\text {th }}$ and $9^{\text {th }}$ days, the speed of healing was lower in the other [28].

Wound healing process consists of inflammation, re-epithelialization, granulation and neovascularization, which result in wound contraction. In histopathological study regarding the inflammation, in $6^{\text {th }}$ day re-epithelialization was not significant in control group, and a little granulation tissue formation was observed. Furthermore, necrotic tissue with severe edema and infiltration of inflammatory cells with dominance neutrophil is visible. In the extract group, there was less inflammatory reaction of neutrophils and edema. Inflammatory infiltration was observed. Furthermore, in addition to neutrophils, a large number of macrophages infiltrated. In wound margins, epithelial hyperplasia occurred. Granulation tissue formation was with angiogenesis. The healing process in silver group was similar to the extract group.

In the $12^{\text {th }}$ day of experiment, incomplete monolayer of epidermal cells (in most of cases, about $30 \%$ of the damaged area was still without re-epithelialization) with evidence of crusting in control group was also observed. Furthermore, granulation tissue with good thickness in the wound edges observed. In some cases, immature granulation tissue with high levels of inflammatory cells in the dermis was seen. In extract group, epidermis exhibited well-structured layers without any crusting. Extract was effective on burn wound with increase in thickness of granulation tissue and re-epithelialization. It also decreased the inflammatory reactions. Although up to $80 \%$ burns in silver were covered by the new re-epithelialization, thickness of re-epithelialization was not significant. Granulation tissue with minimum inflammatory cells in the dermis was made. Re-epithelialization was prominent in extract group.

A. eburnea has been used as a medicinal herb since ancient times in Iran. The present study has shown that the extract from the A. eburnean as an available and inexpensive herb possesses wound healing activity, 
and thus provided the evidence for its traditional use value and it is suitable substitute in healing of burn wounds.

A. eburnea extract to restore burned tissue and facilitate skin regeneration. Moreover, A. eburnea inhibit the growth of microorganisms, therefore, this finding support the use of $A$. eburnea in the management of burn wound infection. In concluded, A. eburnea can be an effective treatment for third-degree burns. Advanced clinical and pharmaceutical studies are recommended to the production of novel natural drugs for burn wound treatment.

\section{REFERENCES}

1. Wu XB, Luo XQ, Gu SY, Xu JH. The effects of Polygonum cuspidatum extract on wound healing in rats. J Ethnopharmacol 2012;141(3):934-7.

2. Manca ML, Zaru M, Bacchetta G, Biggio T, Cappai N, Cabras A, et al. A new technological approach to improve the efficacy of a traditional herbal medicinal product in wound healing. Ind Crops Prod 2015;63:71-8.

3. Bahramsoltani R, Farzaei MH, Rahimi R. Medicinal plants and their natural components as future drugs for the treatment of burn wounds: An integrative review. Arch Dermatol Res 2014;306(7):601-17.

4. Mohajeri G, Masoudpour H, Heidarpour M, Khademi EF, Ghafghazi S, Adibi S, et al. The effect of dressing with fresh kiwifruit on burn wound healing. Surgery 2010;148(5):963-8.

5. Akhoondinasab MR, Khodarahmi A, Akhoondinasab M, Saberi M, Iranpour M. Assessing effect of three herbal medicines in second and third degree burns in rats and comparison with silver sulfadiazine ointment. Burns 2015;41(1):125-31.

6. Fahimi SH, Hajimehdipoor H, Abdollahi M, Mortazavi SA. Burn healing plants in Iranian traditional medicine. Res J Pharmacogn 2015;2(1):53-68

7. Srivastava P, Durgaprasad S. Burn wound healing property of Cocos nucifera: An appraisal. Indian J Pharmacol 2008;40(4):144-6.

8. Khan F, Shah A, Janan A. BURN PATIENTS; Causes of death and factors affecting mortality a 4 years study at a tertiary care hospital. Prof Med J 2013;20(6):1042-7.

9. Ouyang J, Chen YC, Luo GX, Yan H, Peng YZ, Huang YS, et al. A randomized and controlled multicenter prospective study of the Chinese medicinal compound Fufang xuelian burn ointment for the treatment of superficial and deep second-degree burn wounds. Cell Biochem Biophys 2014;69(3):467-74.

10. Priya KS, Gnanamani A, Radhakrishnan N, Babu M. Healing potential of Datura alba on burn wounds in albino rats. J Ethnopharmacol 2002;83(3):193-9.

11. Annan K, Houghton PJ. Antibacterial, antioxidant and fibroblast growth stimulation of aqueous extracts of Ficus asperifolia Miq. and Gossypium arboreum L. wound-healing plants of Ghana. J Ethnopharmacol 2008;119(1):141-4.

12. Houghton PJ, Hylands PJ, Mensah AY, Hensel A, Deters AM. In vitro tests and ethnopharmacological investigations: Wound healing as an example. J Ethnopharmacol 2005;100(1-2):100-7
13. Mantle D, Gok MA, Lennard TW. Adverse and beneficial effects of plant extracts on skin and skin disorders. Adverse Drug React Toxicol Rev 2001;20(2):89-103.

14. Uday P, Achar RR, Bhat RP, Rinimol VR, Bindu J, Nafeesa Z, et al. Laticiferous plant proteases in wound care. Int $\mathrm{J}$ Pharm Pharm Sci 2015;7(1):44-9.

15. Upadhyay NK, Kumar R, Siddiqui MS, Gupta A. Mechanism of wound-healing activity of Hippophae rhamnoides L. Leaf extract in experimental burns. Evid Based Complement Alternat Med 2011;2011:659705

16. Mahmoudvand H, Sharififar F, Rahmat MS, Tavakoli R, Dezaki ES, Jahanbakhsh S, et al. Evaluation of antileishmanial activity and cytotoxicity of the extracts of Berberis vulgaris and Nigella sativa against Leishmania tropica. J Vector Borne Dis 2014;51(4):294-9.

17. Jain N, Argal A. Wound healing potential of young leaves of Triticum aestivum on alloxan induced diabetic rats. Jain Int J Pharm Pharm Sci 2014;5(8):508-13.

18. Eloff JN. Which extractant should be used for the screening and isolation of antimicrobial components from plants? J Ethnopharmacol 1998;60(1):1-8.

19. Madani B, Rahemi M, Baninasab B, Mahmoodi M. Morphological evaluation of three native species of Amygdalus in iran. Hortic Environ Biotechnol 2009;50(1):63-7.

20. Rezaeifar M, Behfarnezhad M, Moradi M, Mehrabani M, Mahmoudvand H. Antibacterial effects of various extracts of Amygdalus eburnea on some most common bacteria in burning. Der Pharm Lett 2016b;8(6):110-2.

21. Rezaeifar M, Mahmoudvand H, Amiria M. Formulation and evaluation of diphenhydramine gel using different gelling agents. Der Pharm Chem 2016e;8(5):243-9.

22. Rezaeifar M, Rezaeifar M. Antioxidant properties of the methanolic extract of the shell root of Amygdalus eburnean. Int J Pharmtech Res 2016d;9(9):514-8.

23. Rezaeifar M, Rezaeifar M. In vitro antidermatophytic effects of the methanolic extract of the Amygdalus eburnean. Int J Pharmtech Res 2016c;9(9):509-12

24. Rezaeifar R, Mousavi SA, Mehrabani M, Sepahvand A. Evaluation of the antifungal effects of various extracts of Amygdalus eburnean on some fungal pathogens. Der Pharm Chem 2016a;8(6):140-2.

25. Mahmoudvand H, Nadri S, Jahanbakhsh S, Rezaeifar M. Evaluations of protoscolicidal activity of Cardamom extract against hydatid cyst protoscoleces. Der Pharm Chem 2016;8(6):91-5.

26. Mahmoudvand H, Nadri S, Rezaeifar M, Rezaeifar M. Scolicidal effects of myrtle methanolic extract on hydatid cyst protoscoleces. Der Pharm Lett 2016;7(8):27-30.

27. Tavakoli Kareshk A, Keyhani A, Mahmoudvand H, Tavakoli Oliaei R, Asadi A, Andishmand M, et al. Efficacy of the Bunium persicum (Boiss) essential oil against acute toxoplasmosis in mice model. Iran J Parasitol 2015;10:625-31.

28. Muhammad HS, Muhammad S. The use of Lawsonia inermis Linn. (Henna) in the management of burn wound infections. Afr J Biotechnol 2005;4(9):934-7. 